\title{
Finite element modelling of a hybrid unreinforced masonry-reinforced concrete wall
}

\author{
F. Frederickx, B. Vandoren \& H. Degée \\ Construction Engineering Research Group, Hasselt University, Hasselt, Belgium
}

\begin{abstract}
The combination of Unreinforced Masonry (URM) and Reinforced Concrete (RC) walls is widely used as bracing system in several countries. This paper deals with the implementation of a numerical model in a commercial finite element software package. The calibration process is described. The objective is to enhance the knowledge of the structural performance of mixed URM-RC systems and, in a subsequent stage, to optimise their design. In this study, we focus on the lateral bracing resistance under statically applied loads. The present numerical campaign fits within a larger project, which aims at optimising the general design of hybrid URM-RC solutions (i.e. the proportion of concrete vs. masonry) as well as the connections used in these hybrid solutions. The long-term objective of the project is the optimisation of the overall lateral load-bearing system.
\end{abstract}

\section{INTRODUCTION}

Masonry and concrete are the most popular construction materials for residential buildings in many countries. The use of hybrid masonry-concrete solutions as lateral bracing systems is beneficial from different points of view. In reality, both materials contribute to the lateral resistance if they are designed properly. However, the contribution of masonry is often neglected. Besides the structural benefit, hybrid solutions are also more sustainable. Non-renewable resources are used for these construction methods. An optimised structure, which takes into account the real contribution of all materials, uses thus the materials more efficiently. Hence, it improves the sustainability.

There exist several types of hybrid masonryconcrete solutions. In this study, we focus on the mixed Unreinforced Masonry (URM) - reinforced concrete (RC) wall structures, see Figure 1. RC walls are added in order to increase the lateral stiffness and strength. The URM and RC walls are coupled by RC beams or slabs. Because of this, the structural behaviour differs from a classic URM building. These systems can be used for the construction of new buildings as well as for strengthening existing URM buildings.

Until recently, few research was available for these hybrid URM-RC wall structures. Last years, several experimental as well as numerical campaigns were carried out at École Polytechnique Fédérale de Lausanne, see Beyer et al. (2015), Paparo \& Beyer (2012, 2013, 2014, 2015b). These campaigns provide a better understanding of the seismic behaviour of mixed URM-RC wall structures and provide a reference set of experimental results. Numerical models (micro and macro) were calibrated and validated. Furthermore, they developed tools for the displacement-based design of hybrid URM-RC wall structures, see Paparo \& Beyer (2015a).

An important conclusion of these experimental campaigns is that the combination of URM and $\mathrm{RC}$ walls results in an actual hybrid behaviour, different from a pure URM one. In a purely URM building, subjected to horizontal loading, the damage tends to concentrate on the ground floor. The addition of concrete walls changes the global behaviour. The RC walls add strength and stiffness to the structure. Due to the connection (i.e. RC beams or slabs) between the URM walls and the $\mathrm{RC}$ walls, the damage is distributed over several floors.

Adding concrete walls on one side of the URM walls implies that symmetry is lost. In this case, the behaviour differs for the two in plane loading directions. For URM walls, an increased level of axial loads results in a decreased deformation capacity (Petry \& Beyer 2014).

This study aims at replicating the results of the numerical campaign presented by Paparo \& Beyer $(2013,2015$ b), in view of further exploitation of the numerical model for optimising URM-RC structural solutions. The test specimen is presented in Figure 1. We will focus on the lateral bracing resistance under an increasing static load. 


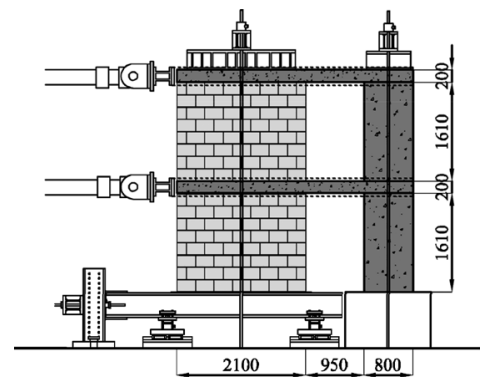

Figure 1. Test unit [mm], adopted from Paparo \& Beyer (2014).

\section{CALIBRATION OF NUMERICAL MODEL}

\subsection{Experimental campaign}

\subsubsection{Test set-up}

Paparo and Beyer (2014) used a four-storey mixed URM-RC building as a reference structure. They selected the outer walls (one URM and one RC) from the first two floors as test unit, see Figure 1. A quasi-static cyclic pushover test is carried out. Two cases were considered: TU1 and TU2. The difference between these two test units is the applied axial load. In the present numerical study, we focus on TU1. Axial loads of $400 \mathrm{kN}$ and $125 \mathrm{kN}$ are applied on top of the URM and RC wall respectively. These axial forces are kept constant during horizontal loading.

The RC wall is connected to a concrete foundation. A steel frame supports the masonry wall. This frame is constructed in such a way that the reaction forces and base moment of the URM wall could be determined easily.

The horizontal loads are applied by two actuators, one for each RC beam. Both actuators carry out the same force, so the test is force-controlled. In order to avoid a modification of the moment capacity (see Paparo and Beyer 2014), the force is not applied at the end of the coupling beams. Instead, the force is distributed over different bars in the beams. These bars are connected to steel beams, which transmit the actuators' forces.

It is a quasi-static cyclic test, so the loads are applied in reversed cycles. The amplitude is increased for each load cycle.

\subsubsection{Material properties}

The URM walls are constructed with vertically perforated clay bricks (tongue-and-groove). Each brick has a length of $300 \mathrm{~mm}$. Their height is $190 \mathrm{~mm}$ and the thickness is $150 \mathrm{~mm}$. The bed joints have a thickness of $10 \mathrm{~mm}$. The head joints contain no mortar.

The RC walls have a thickness of $150 \mathrm{~mm}$. The $\mathrm{RC}$ beams are thicker than the RC walls in order to
Table 1. Material properties TU1 (Paparo \& Beyer 2014).

\begin{tabular}{lcl}
\hline Property & Value & Unit \\
\hline$E_{b x}$ & 9.8 & $\mathrm{GPa}$ \\
$E_{b y}$ & 4.7 & $\mathrm{GPa}$ \\
$E_{c}$ & 36.2 & $\mathrm{GPa}$ \\
$f_{c b x}$ & 23.5 & $\mathrm{MPa}$ \\
$f_{c M}$ & 4.8 & $\mathrm{MPa}$ \\
$\mu$ & 0.6 & $/$ \\
$c$ & 0.41 & $\mathrm{MPa}$ \\
\hline
\end{tabular}

$E_{b x}, E_{b y}$ : Young's moduli of the bricks for loading along the vertical and horizontal axis, respectively

$E_{c}$ : Young's modulus concrete

$f_{c b x}$ : brick compressive strength parallel to perforations

$f_{c M}$ : masonry compressive strength

$\mu$ : friction coefficient

$c$ : cohesion

represent the effective width of the concrete slabs. Paparo \& Beyer (2014) determined a thickness of $450 \mathrm{~mm}$. For the reinforcement schemes, we refer to Paparo \& Beyer (2014).

The most important material properties for TU1 are summarised in Table 1. For the complete set of material data, we refer to Paparo \& Beyer (2014).

\subsection{Numerical model}

The commercial finite element software package DIANA 9.6 is used to model the hybrid URM-RC structure. Other researchers (Al-Chaar \& Mehrabi 2008, Sattar 2013) used DIANA to model RC frames with URM infill panels. They could achieve good agreement between the experimental and numerical results of these hybrid structures, showing the ability of DIANA in modelling such hybrid structures. Coupled URM-RC walls constitutes an extension of its field of application.

A pushover analysis will be performed (loading towards RC wall, see Fig. 1). As mentioned before, a quasi-static cyclic test was performed in the experimental campaign. However, the numerical model does not allow taking into account the cyclic degradation of the masonry. This will most likely result in a stiffer response of the structure in comparison with the experimental test. Since Paparo and Beyer (2013) focussed on the distribution of the axial loads, base shear and base moment, we will try to validate our model against these reference parameters and adjust the material parameters to account for the cyclic degradation in an approximate though commonly accepted manner.

For the URM, a simplified micro-modelling technique (Lourenço 1996a) is used. The bricks are modelled as 2D plane stress continuum elements. 
Zero thickness interface elements are used to represent the joints.

$\mathrm{RC}$ elements are also modelled with 2D plane stress elements. Embedded reinforcement (see Schreppers 2015) is used for the reinforcement bars. The finite element mesh will be described in the following section.

\subsubsection{Finite element mesh}

The initial finite element mesh is presented in Figure 2. We opted to use rectangular elements in order to have a regular layout.

A half brick has four plane stress elements (aspect ratio is 0.75 ). The URM is meshed with four-node quadrilateral elements. A $2 \times 2$ Gauss integration scheme is applied. The same type of elements are used to model concrete. The aspect ratio of the concrete elements is approximately 0.7 and 0.9 for the $\mathrm{RC}$ beams and the $\mathrm{RC}$ walls respectively.

The interface elements are assigned between two lines. Therefore, four-noded interfaces are used and the default integration scheme (three point Newton-Cotes) is applied. Those interfaces are located between bricks (head and bed joints); between bricks and a RC beam and between bricks and the support beam.

In this first mesh, the concrete elements in the beams are aligned with the brick elements. Paparo \& Beyer (2012) divided the RC beams at least into eight elements over the height in order to avoid an incorrect transfer of forces between the walls. Therefore, finer meshes were also generated.

The reinforcement is modelled with 1D truss elements. Embedded reinforcement of DIANA is used for this purpose. We assume perfect bond between reinforcement and concrete. For straightforward extractions, the URM wall is modelled on an elastic (stiff) steel beam.

All elements have a thickness of $150 \mathrm{~mm}$ except for the RC beam elements $(450 \mathrm{~mm})$ and the elastic foundation.

\subsubsection{Boundary conditions}

In the experimental campaign, the $\mathrm{RC}$ wall was connected to a concrete foundation. Therefore,

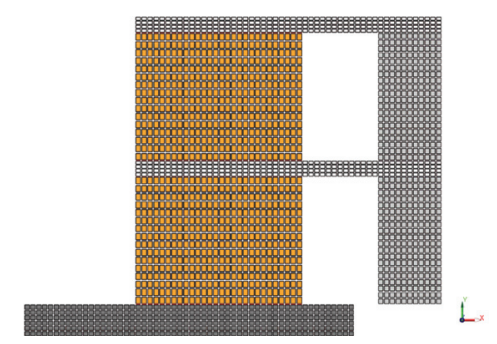

Figure 2. Initial finite element mesh. the bottom nodes of the $\mathrm{RC}$ wall are fixed in vertical and horizontal direction, see Figure $3 \mathrm{a}$ for the boundary conditions of the initial mesh.

The beam under the masonry is restrained in the vertical direction at three locations and in the horizontal direction at one location, see Figure $3 \mathrm{~b}$.

\subsubsection{Loading}

We examine a pushover analysis (towards the RC wall) of TU1. Therefore the load control for the horizontal actions is force-controlled. The horizontal loads are applied on several nodes in the RC beam. The load is distributed over the two walls. This distribution is proportional to the length of the walls. An allocation of approximately $70 \%$ (URM) and 30\% (RC) was used (see Paparo \& Beyer 2014). The force applied at the first floor is equal to the one applied at the second floor.

The vertical loads are applied prior to horizontal loading and directly on top of the upper RC beam. $400 \mathrm{kN}$ is divided over some of the upper nodes of the $\mathrm{RC}$ beam which are located above the masonry wall. The same is applicable to the axial load $(125 \mathrm{kN})$ on top of the RC walls. Additional vertical forces (supplement for self-weight and supported test set-up) were applied in order to replicate the vertical reaction forces of approximately $460 \mathrm{kN}$ and $150 \mathrm{kN}$ at the base of the URM and $\mathrm{RC}$ walls respectively.

\subsubsection{Material models}

The bricks are modelled with a smeared crack material model. The input parameters are presented in Table 2. The fracture energies are estimated according to the recommendations of Lourenço (2008). The Young's modulus lies in between $E_{\mathrm{b} x}$ and $E_{\mathrm{b} y}$ (see Table 1).

Concrete is also modelled with a smeared crack model. The parameters are listed in Table 3. An exponential tensile behaviour is assumed. The mode I fracture energy $\left(G_{f}^{I}\right)$ is calculated with the formula presented in the Model Code 2010 (2013). The compression curve of the Model Code 2010 (2013) is applied to model the compressive behaviour.

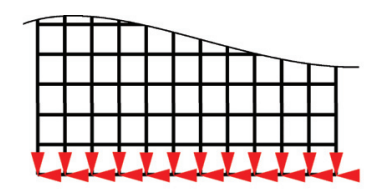

(a)

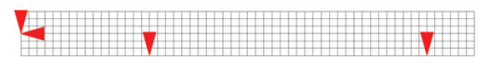

(b)

Figure 3. Boundary conditions for the initial finite element mesh: (a) RC wall, (b) URM support beam. 
The bed joints and URM-RC joints are modelled with the combined cracking-shearing-crushing interface model of DIANA. Lourenço (1996b) presents several recommendations for this composite interface model. $\mathrm{G}_{\mathrm{f}}^{\mathrm{I}}$ can be estimated as an average value of $0.012 \mathrm{~N} / \mathrm{mm}$, for $\mathrm{G}_{\mathrm{f}}^{\mathrm{II}} 1 / 10$ of the cohesion is advised. However, in order to replicate the results of Paparo \& Beyer (2015b), $0.41 \mathrm{~N} / \mathrm{mm}$ and $0.5 \mathrm{~N} / \mathrm{mm}$ are used for $\mathrm{G}_{\mathrm{f}}^{\mathrm{I}}$ and $\mathrm{G}_{\mathrm{f}}{ }_{\mathrm{II}}$ respectively. $\mathrm{C}_{\mathrm{s}}$, a parameter which is necessary for the compression cap, is recommended to be 9 . The cohesion and the friction coefficient are experimentally determined, i.e. $0.38 \mathrm{MPa}$ and 0.63 . The bond tensile strength is $0.3 \mathrm{MPa}$ according to Paparo and Beyer (2015b). The normal and tangential stiffness of the bed joints are $300 \mathrm{~N} / \mathrm{mm}^{3}$ and $10 \mathrm{~N} / \mathrm{mm}^{3}$ respectively. The latter parameters were calibrated by Paparo and Beyer (2015b) in order to match the Young's modulus of the masonry. For the compressive fracture energy, the formula proposed in Model Code 90 is used. The dilatancy angle is assumed to be $0^{\circ}$.

For the empty head joints, two models were tested in order to avoid interpenetration of the bricks. A discrete crack model and a nonlinear elasticity model. Both models had a similar output. The behaviour is stiff in compression and weak in tension (simulation of an empty joint). It is assumed that shear forces are not transmitted. The application of these vertical interfaces did not influence the behaviour of the structure significantly. A model without these head joints had a similar output.

A von Mises plasticity model is used for the reinforcement $\left(\mathrm{f}_{\mathrm{y}}=540 \mathrm{MPa}\right)$.

Table 2. Brick parameters.

\begin{tabular}{lll}
\hline Property & Value & Unit \\
\hline Young's modulus & 5600 & $\mathrm{MPa}$ \\
Poisson's coefficient & 0.2 & $/$ \\
Tensile strength & 1.4 & $\mathrm{MPa}$ \\
Mode I fracture energy & 0.0406 & $\mathrm{~N} / \mathrm{mm}$ \\
Compressive strength & 23.5 & $\mathrm{MPa}$ \\
Compressive fracture energy & 23.12 & $\mathrm{~N} / \mathrm{mm}$ \\
\hline
\end{tabular}

Table 3. Concrete parameters.

\begin{tabular}{lll}
\hline Property & Value & Unit \\
\hline Young's modulus & 33,000 & $\mathrm{MPa}$ \\
Poisson's coefficient & 0.2 & $/$ \\
Tensile strength & 3 & $\mathrm{MPa}$ \\
Mode I fracture energy & 0.147 & $\mathrm{~N} / \mathrm{mm}$ \\
Compressive strength & 50 & $\mathrm{MPa}$ \\
\hline
\end{tabular}

\subsubsection{Results FE model}

In the experimental campaign, the following values were set to zero after the application of the vertical loads: applied horizontal force; base shear; base moment; variation of the axial forces and the drift. Therefore, these parameters are also set to zero in our numerical campaign. Hence, relative values are considered in this section (with respect to the moment of application of the vertical loads).

The results of a force-controlled analysis with the initial mesh (Fig. 2) is presented in Figures 4-5. Since the input parameters were based on the ones of Paparo \& Beyer (2015b), it was expected to obtain similar results. However, not all parameters were mentioned, so differences in input parameters are possible. Furthermore, the material models are not identical.

Figures 4-5 indicate that, although the global trends are correctly captured by a model using raw material properties, a better agreement could however be achieved between the experimental results and our numerical model. The vertical force is transferred too fast to the RC wall, while, concerning the base shear, the initial response is too stiff.

Several parameters were then changed in order to make the results match. Mesh refinement was also tested but yielded no better results. However,

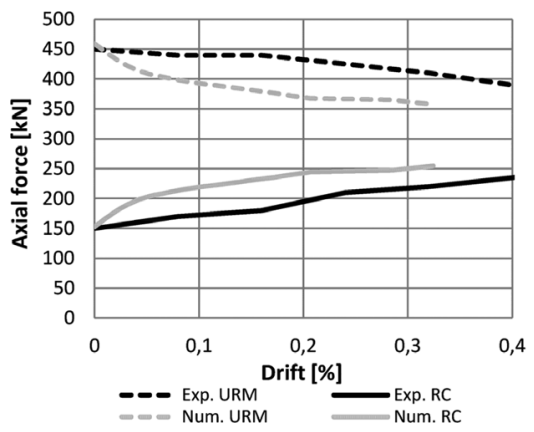

Figure 4. Axial force versus drift.

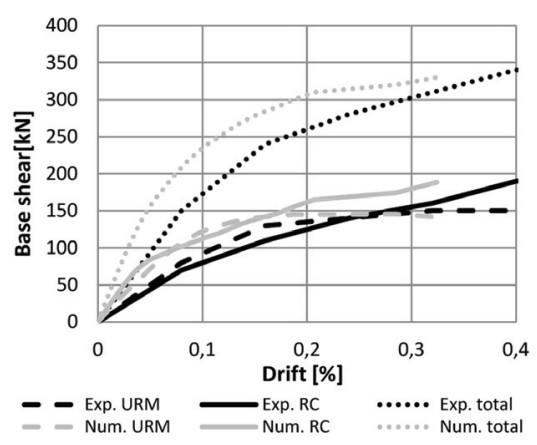

Figure 5. Variation of base shear versus drift. 
good agreement was not achieved. Consequently, it was necessary to reassess the input parameters. In order to tackle this problem, we first tried to find good agreement in the elastic regime. Therefore, the applied horizontal forces were limited. Based on the experimental observations, the elastic regime is assumed to occur up to a total horizontal load of $100 \mathrm{kN}$ (for the first load cycles and pushing towards the $\mathrm{RC}$ wall). The variation of axial loads, base shear, base moment and the displacements were plotted for this range of horizontal loads. It was observed that there was a primarily linear trend for all parameters in this range and direction. However, it was noted that the applied axial load was changed in a certain load cycle during the experiment. An extra vertical load of almost $10 \mathrm{kN}$ was applied. Therefore, the values at $100 \mathrm{kN}$ were estimated using the slope of the first cycle of the experimental results.

A numerical simulation was performed in this elastic range. It concerns a pushover test with horizontal loading towards the $\mathrm{RC}$ walls. The results are displayed in Figures 6-8. In comparison with the initial mesh (Fig. 2), a finer mesh is used.

Figure 6 shows that the transfer of the axial load is overestimated by the numerical model, indi-

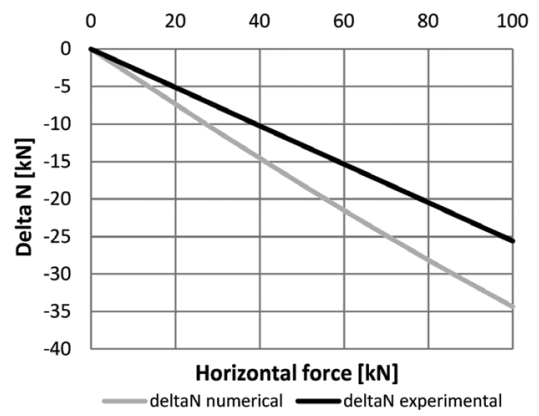

Figure 6. Variation of axial force (delta N) in URM wall.

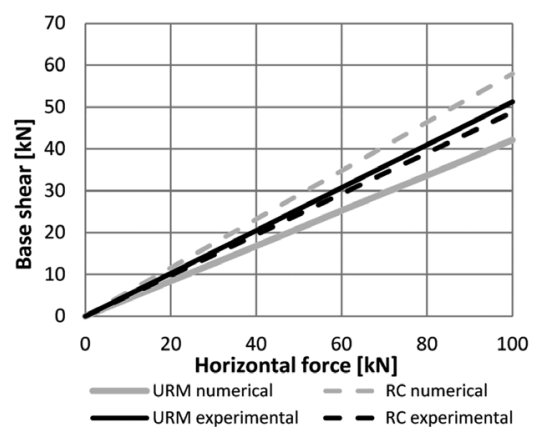

Figure 7. Variation of base shear. cating that the transferred shear forces through the beams are incorrect.

The base shear was almost equally divided over the two walls in the experimental campaign for this range of horizontal forces (see Fig.7). The numerical model predicts a larger base shear in the RC wall.

The evolution and distribution of the base moment in the two walls is also not well captured (see Fig. 8). In the experimental campaign, the base moment in the URM wall was significantly larger than the one in the $\mathrm{RC}$ wall. The base moments are almost equal according to the numerical model. The overestimation of the transferred axial force partly explains a difference in the distribution of base moment. After all, an increased axial load compensates the overturning moment to a greater extent.

The displacement of the top beam is underestimated. The numerical value is around 0.8 times the measured displacement.

Based on these results, it is concluded that a blind choice of material properties coupled with a rather classical modelling approach does not allow matching the experimental results. In order to facilitate the examination of the influence of different elastic input parameters, the structure was also analysed by resorting to a simplified frame model.

\subsubsection{Elastic frame model}

In the elastic frame model, the walls and beams are modelled as beam elements. Those beams are placed at the centrelines of the actual walls. The distance between the two walls is therefore $2.4 \mathrm{~m}$. Reinforcement is neglected in this model, so the RC members have the properties of unreinforced concrete.

Rigid offsets are applied at both ends of the concrete beams in order to represent the continuous beams, see Figure 9. The length of the rigid offsets is initially half the length of the walls. Paparo \& Beyer (2012) also used rigid offsets for their macro element. The software TREMURI was used for their macro model. They applied an elasto-plastic

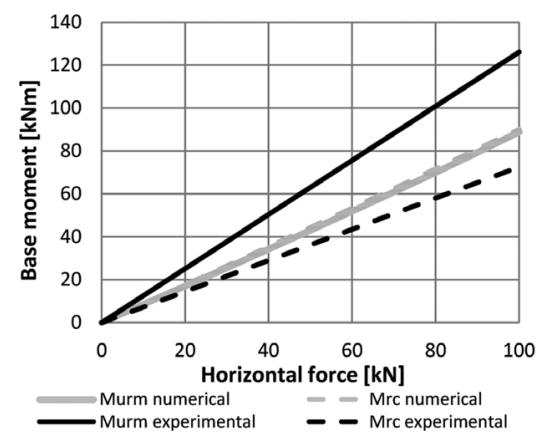

Figure 8. Variation of base moment. 
law for the RC elements (plasticity concentrated at elements ends). A homogenised continuum represents the URM walls. For these walls, the relation between average stress and strains is described.

Our elastic frame model shows a similar behaviour as the finite element model if the same elastic parameters are used, see Figures 10-12. However, the FE model predicts a more even distribution of the base moment and the transfer of axial loads is more realistic. For the frame model, a lower shear modulus was applied. Paparo \& Beyer (2015b) suggest a shear modulus of $540 \mathrm{MPa}$ (for a Young's modulus of $5100 \mathrm{MPa}$ ). This reduced shear modulus appeared to be important for a more realistic estimation of the displacements.

Some trial tests were carried out in order to achieve good agreement for the reference parameters (base shear, axial force, base moment and top displacement). In particular, the Young's moduli of the different members were varied (extreme values in order to check the influence). It was concluded that the best variations were: (i) stiffer URM walls; (ii) less stiff RC beams and (iii) less stiff RC walls. These solutions resulted in a better agreement for most experimental values (base shear, base moment and axial force).

A more flexible RC beam can also be realised by increasing its free (or effective) length. Hence, shorter rigid links can be applied on the side of the URM walls. Paparo \& Beyer (2015b) increased the effective length of the beams (in the macro model) with their section depth. They conducted a parametric study and concluded that the length was well estimated.

The influence of an increased effective length was investigated using the frame model. There-

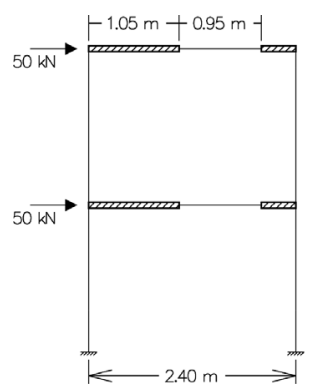

Figure 9. Elastic frame model: pushover.

Table 4. Influence effective length: elastic input parameters.

\begin{tabular}{lll}
\hline Property & Value & Unit \\
\hline$E_{\mathrm{URM}}$ & 5100 & $\mathrm{MPa}$ \\
$G_{\mathrm{URM}}$ & 540 & $\mathrm{MPa}$ \\
$E_{\mathrm{RC}}$ & 18,000 & $\mathrm{MPa}$ \\
$V_{\mathrm{RC}}$ & 0.2 & $/$ \\
\hline
\end{tabular}

fore, a pushover test was performed (see Fig. 9). The length was varied between $0.95 \mathrm{~m}$ and $1.65 \mathrm{~m}$. The elastic parameters are listed in Table 4. An increased length results in a better estimation of most reference parameters (in comparison with the reference structure depicted in Figure 9). However, this results in larger displacements and an increased base moment at the $\mathrm{RC}$ wall.

It is concluded that various parameters affect the global (elastic) behaviour of the structure. It is not easy to achieve good agreement between experimental and numerical results. Different

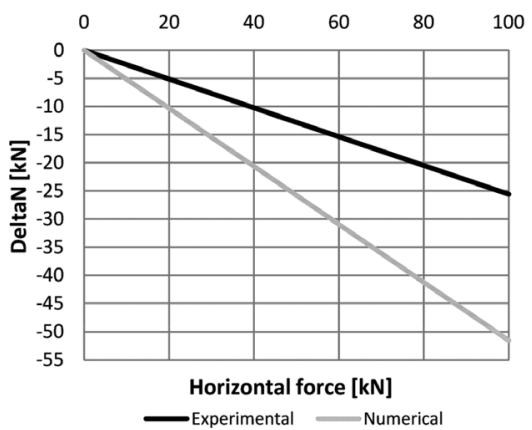

Figure 10. Frame model: variation of axial force (deltaN) in URM wall.

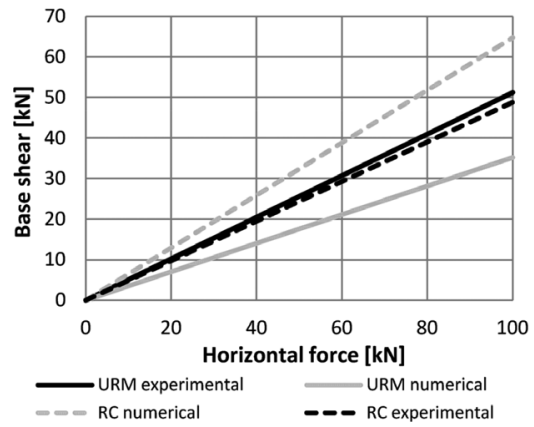

Figure 11. Frame model: variation of base shear.

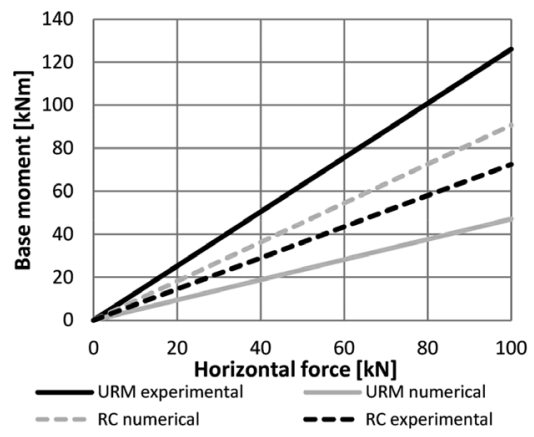

Figure 12. Frame model: variation of base moment. 
combinations of modified parameters might lead to the same solution. To ease the selection of appropriate parameters, a parametric analysis was implemented in MATLAB. The Young's moduli of the RC walls, the URM walls and the $\mathrm{RC}$ beams were varied. Also the effective length was varied. The extreme values and the step sizes are listed in Table 5. Two types of analyses were performed: (i) assumption of a fixed shear modulus for URM and (ii) a fixed Poisson's coefficient. The structure is analysed for all the combinations of the varied parameters (see Table 5). The results of these analyses are filtered based on a maximum deviation (percentage) on the experimental results (variation of axial load, base shear, base moment and beam displacement). The filtered solutions are than assessed for suitability.

For the analyses with a constant shear modulus (540 MPa), $E_{\text {URM }}$ has to increase up to $18,000 \mathrm{MPa}$ in order to have a maximum deviation of $6 \%$ on the experimental values. The other parameters are more realistic.

If the Poisson's ratio is constant, the Young's moduli are more realistic for the URM walls as well as for the RC walls. However, the stiffness of the beams has to decrease (lower Young's modulus or an increased effective length). A deviation of minimum $15 \%$ on the experimental values had to be allowed in order to find possible solutions.

In conclusion, it can be stated that it is rather difficult to obtain good agreement in the elastic regime. The calibrated frame model was supposed to be used to re-think the finite element model. The frame model confirmed two important insights: (i) the URM walls are not stiff enough in comparison with the RC walls and (ii) the RC beams are too stiff. However, increasing the Young's modulus of the URM walls in such an extent is not realistic. Therefore, we will examine a reduction of the stiffness of the RC elements by changing its non-linear behaviour.

\subsubsection{FE model with adjusted non-linear behaviour}

The results of a FE analysis with a decreased mode I fracture energy for concrete are presented in Figures 13-15. The fracture energy presented in Table 3 is approximately divided by a factor 10 . The FE mesh is more fine than the one presented

Table 5. Parameters parametric analysis frame model.

\begin{tabular}{lllll}
\hline Property & Minimum & Step & Maximum & \\
\hline$E_{\mathrm{URM}}$ & 4000 & 1000 & 20,000 & $\mathrm{MPa}$ \\
$E_{\mathrm{RC} \text { beam }}$ & 4000 & 2000 & 30,000 & $\mathrm{MPa}$ \\
$E_{\mathrm{RC} \text {,wall }},{ }^{\text {st }}$ & 10,000 & 2000 & 36,000 & $\mathrm{MPa}$ \\
$E_{\mathrm{RC} \text {,wall, }} 2^{\text {nd }}$ & 16,000 & 2000 & 36,000 & $\mathrm{MPa}$ \\
$L_{\text {eff }}$ & 0.95 & 0.1 & 1.95 & $\mathrm{~m}$ \\
\hline
\end{tabular}

in Figure 2. The deformed shape (magnifying factor: 100) and the cracked zones are depicted in Figures 16-17.

The results are in closer agreement with the experimental values (compare with Figures 4-5). Hence, the results are more promising. However numerical problems arose at a certain load step, the solution did not converge. Further improvements should be implemented in order to overcome these obstacles.

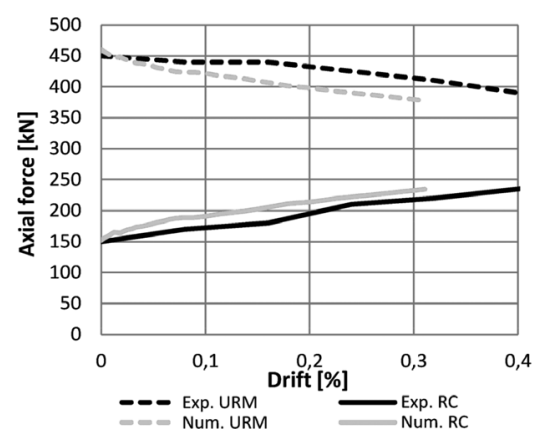

Figure 13. Axial force versus drift.

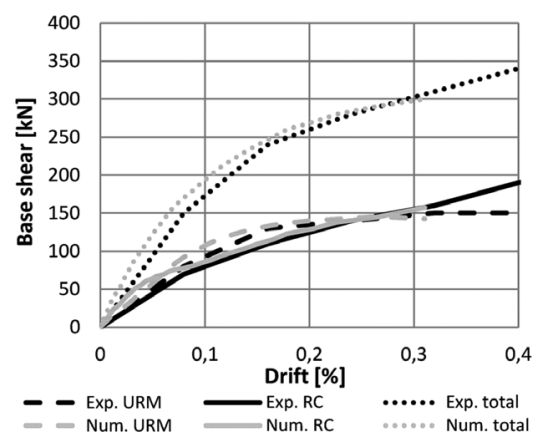

Figure 14. Base shear versus drift.

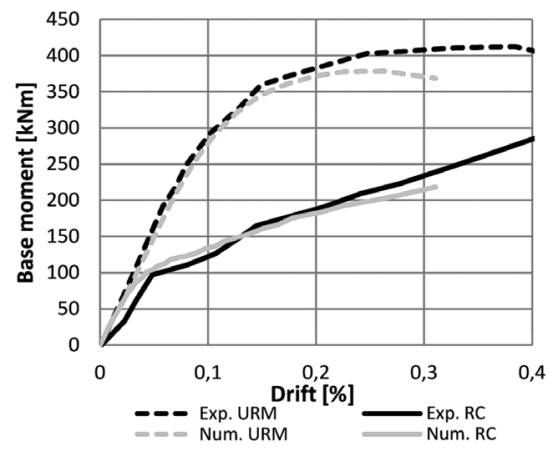

Figure 15. Base moment versus drift. 


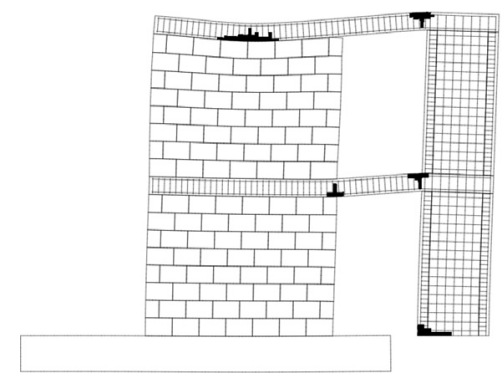

Figure 16. Deformed shape and cracked zones $($ drift $=0.04 \%)$.

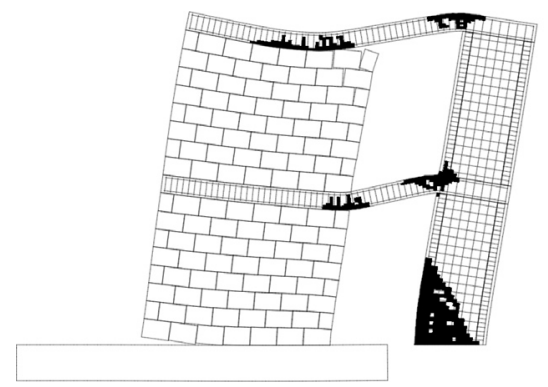

Figure 17. Deformed shape and cracked zones $($ drift $=0.17 \%)$.

\section{CONCLUSION}

A finite element model of a mixed URM-RC wall structure was implemented in the commercial finite element software DIANA. The objective was to perform a blind calculation and see if it could match with the experimental results.

The results of the finite element model using standard material and contact properties exhibit a limited agreement with the experimental results. Especially in the elastic regime some significant differences were observed. In order to further investigate the reasons of such discrepancy, a more simple elastic frame model was derived and calibrated against the experimental results (for the elastic range). This calibrated model was used to re-think the finite element model. It provided insight in the behaviour of the finite element model. In general, the URM walls were not stiff enough in comparison with the RC walls and the RC beams were too stiff. Adjustment of the elastic parameters was rather unrealistic and did not resolve the discrepancies. Therefore, the fracture energy of the concrete elements was adjusted. This resulted in a better agreement with the experimental results but the behaviour in the elastic regime still shows inconsistency with the experimental results. Some numerical problems arose during the analysis and further efforts should be made in order to capture the complete behaviour.
The calibrated model will be used to perform parametric analyses on global structural parameters. These analyses will contribute to a better understanding of these hybrid structures. They can also be used for the optimisation of hybrid URM-RC structures.

\section{ACKNOWLEDGEMENT}

The first author thanks Hasselt University for the financial support of the research.

\section{REFERENCES}

Al-Chaar, G.L., Mehrabi, A. 2008. Constitutive models for nonlinear finite element analysis of masonry prisms and infill walls (No. ERDC/CERL TR- 08-19), US Army Corps of Engineering.

Beyer, K., Tondelli, M., Petry, S., Peloso, S. 2015. Dynamic testing of a four-storey building with reinforced concrete and unreinforced masonry walls: prediction, test results and data set. Bulletin of Earthquake Engineering.

International Federation for Structural Concrete (FIB) 2013. Model Code for Concrete Structures 2010.

Lourenço, P.B. 1996a. Computational strategies for masonry structures. Delft University Press, Delft, The Netherlands.

Lourenço, P.B. 1996b. A user/programmer guide for the micro-modeling of masonry structures (No. 03.21.1.31.35). Delft University of Technology, The Netherlands.

Lourenço, P.B. 2008. Structural masonry analysis: Recent developments and prospects.

Paparo, A., Beyer, K. 2012. Pushover analyses of mixed RC-URM wall structures, in: Proceedings of the 15th World Conference on Earthquake Engineering.

Paparo, A., Beyer, K. 2013. Seismic behaviour of mixed RC-URM wall structures: comparison between numerical results and experimental evidence, in: Proceedings of the Vienna Congress on Recent Advances in Earthquake Engineering and Structural Dynamics.

Paparo, A., Beyer, K. 2014. Quasi-static cyclic tests of two mixed reinforced concrete-unreinforced masonry wall structures. Engineering Structures 71: 201-211.

Paparo, A., Beyer, K. 2015a. Development of a displacement-based design approach for modern mixed RCURM wall structures. Earthquakes and Structures 9: 789-830.

Paparo, A., Beyer, K. 2015b. Modelling the seismic response of modern URM buildings retrofitted by adding RC walls. Journal of Earthquake Engineering.

Petry, S., Beyer, K. 2014. Influence of boundary conditions and size effect on the drift capacity of URM walls. Engineering Structures 65: 76-88.

Sattar, S. 2013. Influence of masonry infill walls and other building characteristics on seismic collapse of concrete frame buildings. University of Colorado.

Schreppers, G. 2015. Embedded Reinforcements. TNO DIANA BV, The Netherlands. 